\title{
Evaluation of a directly observed six month fully intermittent treatment regimen for tuberculosis in patients suspected of poor compliance
}

\author{
J A Caminero, J M Pavón, F Rodríguez de Castro, F Díaz, G Julià, J A Caylá, P Cabrera
}

\begin{abstract}
Background - Although a priority for tuberculosis control is to achieve the maximum cure rate, compliance with chemotherapy in specific high risk groups (homeless, intravenous drug abusers, chronic alcoholics) is usually poor.

Methods - From January 1990 to December 1994102 patients with tuberculosis (96 pulmonary, six extrapulmonary) who were poorly compliant with treatment were treated with a six month fully intermittent (twice weekly) directly observed regimen. They comprised 71 homeless subjects, 50 chronic alcoholics, 23 intravenous drug abusers, nine infected with HIV, and 11 who had previously abandoned a daily antituberculosis regimen; 53 had more than one of these risk factors. Treatment included isoniazid and rifampicin for six months and pyrazinamide during the first two months. Patients who failed to take their medication on two consecutive occasions were actively sought by telephone or by personal search.
\end{abstract}

Results - After two months of treatment 95 of the 102 patients had taken their medication regularly and 90 of them had negative cultures. Four of the remaining patients had negative cultures after three months. At the end of the six months 87 patients had completed treatment and were considered cured. Only 15 patients abandoned the treatment (13 of whom had more than one risk factor). Only three relapses occurred in the 102 patients at one year follow up and in the 88 patients followed for two years. Two patients required a change of treatment due to major side effects. Although intravenous drug abuse was the only predictor of noncompliance in the multivariate analysis, if the available variables in the second month of treatment were analysed, current poor compliance and abandonment of treatment in the past were found to be significantly associated with non-compliance.

Conclusions - This study shows the efficacy of this intermittent regimen and the effectiveness of a directly observed treatment programme.

(Thorax 1996;51:1130-1133)

Keywords: tuberculosis, directly observed intermittent therapy, compliance.
The aim of all antituberculosis programmes is to increase the cure rate of patients receiving treatment. ${ }^{1-3}$ Although achievement of this goal is hindered by unfavourable socioeconomic and organisational conditions in developing countries, the implementation of appropriate controlled programmes based on short term chemotherapy has proved successful in obtaining a high cure rate amongst smear-positive patients. ${ }^{45}$ In industrialised countries the high incidence of elective termination of treatment registered amongst drug abusers, the homeless, and alcoholics has become a matter of concern. $^{6-9}$

In order to increase the cure rate it may be necessary to supervise the administration of all medications strictly ${ }^{10}$ and, in developing countries, to find low cost and effective regimens. Twice weekly treatment for 4-8 days is needed to reinitiate bacillary multiplication after exposing mycobacteria to bactericidal drugs $^{1112}-$ this regimen not only facilitates cost reduction and supervision of treatment but has been found to be as effective as daily antituberculosis regimens. ${ }^{13-16}$

We assessed the effectiveness of a six month fully intermittent (twice weekly) treatment regimen in specific high risk groups likely to be non-compliant such as the homeless, chronic alcoholics, intravenous drug abusers, and patients who had previously abandoned daily antituberculosis treatment.

\section{Methods}

All patients with tuberculosis at risk of noncompliance who attended our hospital between January 1990 and December 1994 were eligible for inclusion in the study. The criteria for inclusion were a definitive diagnosis of tuberculosis based on laboratory identification of Mycobacterium tuberculosis, being homeless with no fixed abode and/or intravenous drug addict and/or a chronic alcoholic. Patients who had previously abandoned a dạily antituberculosis regimen were also included provided that drug susceptibility testing excluded the presence of resistance to the drugs administered.

Intermittent antituberculosis treatment consisted of a six month regimen in which isoniazid $(15 \mathrm{mg} / \mathrm{kg}$ per dose) and rifampicin $(10 \mathrm{mg} / \mathrm{kg}$ per dose up to $600 \mathrm{mg}$ ) were given twice a week (Monday and Thursday) for six months and pyrazinamide $(60 \mathrm{mg} / \mathrm{kg}$ per dose) during the first two months. According to our rate of initial resistance ${ }^{17}$ neither systematic sensitivity 
testing nor the use of a fourth drug in the first phase of treatment ${ }^{18}$ appeared to be justified. During the first two months of treatment and while waiting for the results of drug sensitivity testing ethambutol $(50 \mathrm{mg} / \mathrm{kg}$ per dose) was given to patients who had previously abandoned daily antituberculosis treatment. Drug sensitivity testing was only carried out in those with a positive culture in the second month of treatment. ${ }^{19}$

Patients were requested to attend the hospital regularly for supervision of medication. At each visit they were informed about the seriousness of mycobacterial infection and the importance of compliance with the treatment regimen was stressed. They were also given a meal. A nurse supervised the procedure. Patients who failed to take their medication on two consecutive occasions were actively sought by telephone or by personal search. Most of the missing homeless were found in shelters.

A physical examination was carried out two weeks after starting treatment, at one, two, four and six months of treatment, and at six, 12, 18, and 24 months after completion of treatment. Bacteriological and biochemical investigations were performed at all visits and radiological studies were carried out at the beginning and at the end of treatment.

To assess the pharmacological effectiveness of intermittent antituberculosis treatment the following variables were analysed: percentage of patients with negative cultures at two months of treatment; number of patients with positive cultures at three months of treatment (pharmacological failures); percentage of patients in whom medication was discontinued or changed due to side effects; number of relapses at 24 months after completion of treatment; and number of patients cured (culture negative). Depending on the number of doses taken at the second, fourth, and sixth month, patients were divided into those who had taken all the required doses, those who had taken $75-99 \%$ of the required doses, those who had taken $50-75 \%$ of doses, and those who had taken less than $50 \%$. Before finishing the programme patients were also classified into those who were compliant and those who had abandoned treatment.

\section{DATA ANALYSIS}

Statistical analyses were carried out by using the $\chi^{2}$.test (with Yates' continuity correction when needed) and the odds ratio (OR) with $95 \%$ confidence intervals (CI). A logistic regression model was used to analyse predictive variables of non-compliance at the time of diagnosis and at the end of the second month of treatment. A p value of $<0.01$ was considered to be statistically significant. All calculations were performed with the SPSS-PC and EGRET statistical packages.

\section{Results}

During the study period (January 1990 to December 1994) 104 patients with culture positive tuberculosis were included in the study, al-
Table 1 Compliance with intermittent antituberculosis treatment $(n=102)$

\begin{tabular}{llll}
\hline $\begin{array}{l}\text { Percentage of doses taken } \\
\text { under nurse supervision }\end{array}$ & \multicolumn{3}{l}{$\begin{array}{l}\text { No of patients attending to take drugs } \\
\text { regularly }\end{array}$} \\
\cline { 2 - 4 } & 2nd month & 4th month & 6 th month \\
\hline $100 \%$ & 59 & 40 & 37 \\
$75-99 \%$ & 32 & 37 & 38 \\
$50-74 \%$ & 4 & 10 & 11 \\
$<50 \%$ & 0 & 1 & 1 \\
Abandonments & 7 & 14 & 15 \\
Culture negative $^{a}$ & 90 & 88 & 87 \\
\hline
\end{tabular}

${ }^{\text {a }}$ Sputum conversion.

though two patients were excluded later because of side effects leaving a study population of 102 patients for analysis. Their age ranged from 18 to 87 years (mean 41.3 years) and 84 were men. Homelessness was registered in 71 patients, chronic alcoholism in 50 , intravenous drug abuse in 23, and abandonment of previous treatment in 11. At least two of these conditions was present in 53 patients. Nine patients were seropositive for the human immunodeficiency virus (HIV), all of whom used heroin by the intravenous route. Pulmonary tuberculosis was diagnosed in 96 patients and extrapulmonary tuberculosis in six. Smear positive $M$ tuberculosis was found in 94 patients and eight were smear negative.

Table 1 shows the rate of compliance of the patients throughout the six month treatment period. At the end of the second month 95 patients attended the sessions regularly and 90 had negative cultures. Of the five patients with positive cultures one was lost to follow up shortly afterwards and four had negative cultures at three months. None of these five patients exhibited resistance to the drugs administered. At the end of the fourth and six months 88 and 87 patients, respectively, continued taking medications and all of them had negative $M$ tuberculosis cultures. At the end of six months only 15 patients had abandoned treatment, 13 of whom had more than one risk factor at the time of inclusion in the study. Two patients who discontinued treatment (both during the first month) sought medical care 13 and 18 months later because of active pulmonary tuberculosis; none of the other patients appear to have been treated at the other hospitals in Gran Canaria.

The results of univariate analysis are shown in table 2. Abandonment of treatment occurred more frequently in women, in those aged under 55 years, and in those with extrapulmonary tuberculosis, smear positive tuberculosis, HIV seropositivity, homelessness, chronic alcoholism, intravenous drug abuse, abandonment of treatment in the past, and poor adherence to treatment at the second month. The five women who dropped out were intravenous drug abusers and indigents (table 2). Low compliance at two months was the only variable significantly associated with abandonment of treatment $(\mathrm{p}<0.0001)$.

At the time of diagnosis intravenous drug abuse was the only statistically significant variable in the multivariate analysis (OR 4.62; 95\% CI 1.21 to $17.54 ; \mathrm{p}=0.02$ ) although homelessness, chronic alcoholism, and abandonment 
Table 2 Results of univariate analysis. Predictors of poor compliance

\begin{tabular}{|c|c|c|c|c|}
\hline Variable & Total & Cured & Abandonments (\%) & Odds ratio $(95 \% \mathrm{CI})$ \\
\hline \multicolumn{5}{|l|}{ Age } \\
\hline $18-39^{a}$ & 49 & 41 & $8(16.3)$ & \\
\hline $40-54$ & 37 & 31 & $6(16.2)$ & $0.99(0.38$ to 2.53$)$ \\
\hline$>55$ & 16 & 15 & $1(6.2)$ & $0.34(0.04$ to 2.77$)$ \\
\hline Women $^{a}$ & 18 & 13 & $5(27.7)$ & \\
\hline Men & 84 & 74 & $10(11.9)$ & $0.35(0.10$ to 1.15$)$ \\
\hline Extrapulmonary $\mathrm{TB}^{\mathrm{a}}$ & 6 & 4 & $2(33.3)$ & \\
\hline Pulmonary TB & 96 & 83 & $13(13.5)$ & $0.31(0.05$ to 1.75$)$ \\
\hline Smear negative ${ }^{a}$ & 8 & 7 & $1(12.5)$ & \\
\hline Smear positive & 94 & 80 & $14(14.9)$ & $1.22(0.13$ to 10.78$)$ \\
\hline HIV seronegative & 93 & 81 & $12(12.9)$ & \\
\hline HIV seropositive & 9 & 6 & $3(33.3)$ & $3.38(0.79$ to 14.38$)$ \\
\hline \multicolumn{5}{|l|}{ Homelessness } \\
\hline $\mathrm{No}^{\mathrm{a}}$ & 31 & 28 & $3(9.6)$ & \\
\hline Yes & 71 & 59 & $12(16.9)$ & $1.90(0.50$ to 7.19$)$ \\
\hline \multicolumn{5}{|l|}{ Drug abuse (iv) } \\
\hline $\mathrm{No}^{\mathrm{a}}$ & 79 & 70 & $9(11.4)$ & \\
\hline Yes & 23 & 17 & $6(26.0)$ & $2.75(0.88$ to 8.54$)$ \\
\hline \multicolumn{5}{|l|}{ Chronic alcoholism } \\
\hline $\mathrm{No}^{\mathrm{a}}$ & 52 & 46 & $6(11.5)$ & \\
\hline Yes & 50 & 41 & $9(18.0)$ & $1.68(0.55$ to 5.12$)$ \\
\hline \multicolumn{5}{|l|}{ Abandonment of } \\
\hline $\mathrm{No}^{\mathrm{a}}$ & 91 & 79 & $12(13.2)$ & \\
\hline Yes & 11 & 8 & $3(27.3)$ & $2.47(0.59$ to 10.3$)$ \\
\hline \multicolumn{5}{|l|}{ Compliance 2nd month } \\
\hline $100 \%^{\mathrm{a}}$ & 58 & 58 & $1(1.7)$ & \\
\hline$>75 \%$ & 32 & 28 & $4(12.5)$ & $8.29(1.20$ to 57.05$)$ \\
\hline $50-75 \%$ & 4 & 1 & $3(75.0)$ & 174 (30.18 to 10003.15$)$ \\
\hline$<50 \%$ & 7 & 0 & $7(100)^{b}$ & $406(75 \text { to } 2197.77)^{\mathrm{c}}$ \\
\hline Total & 102 & 87 & $15(14.7)$ & \\
\hline
\end{tabular}

${ }^{\mathrm{a}}$ Reference category; ${ }^{\mathrm{b}} \mathrm{p}<0.0001 ;{ }^{\mathrm{c}}$ Approximate estimation.

of previous treatment almost reached statistical significance $(p \geq 0.1)$. At the end of the second month of treatment abandonment of past treatment was significantly associated with noncompliance (OR 8.87; 95\% CI 1.15 to 68.15; $\mathrm{p}<0.05)$.

Only three relapses occurred in the 102 patients followed up for one year and in the 88 patients followed for two years. The relapse rate at two years was $3.4 \%$. The three relapses at one year occurred in an indigent patient, a patient who was an intravenous drug abuser and a chronic alcoholic, and another who had been non-compliant with treatment in the past.

Two patients were excluded from the analysis because of side effects which required a change of treatment (a case of "flu-like" syndrome attributed to the intermittent use of rifampicin and one of hepatitis associated with isoniazid). Eleven patients experienced transient side effects including gastric symptoms (seven), itching (three), and arthralgia with hyperuricaemia (one).

\section{Discussion}

At present the ideal antituberculosis regimen consists of daily administration of isoniazid and rifampicin for six months, reinforced with pyrazinamide during the first two months. In areas with high rates of primary resistance ethambutol is added in the initial phase. ${ }^{13-16}$ Regimens based on partial or fully intermittent administration of drugs are well established and have also been recommended. These include an initial two month period of daily administration, the use of four drugs in the initial phase, and the administration of drugs three times per week. ${ }^{131520-26}$ However, a few studies of fully intermittent twice weekly regimens have been carried out with discouraging results. ${ }^{27-29}$ In the study by Paramasivan et a ${ }^{28}$ only $80 \%$ of patients were culture negative at the end of treatment, $49 \%$ did not complete the short course chemotherapy regimen, and no data on relapses were given. We have obtained much better results using the same intermittent antituberculosis regimen which indicates the importance of directly observing drug taking in the success of this therapeutic strategy. Our findings are similar to those obtained in New York city, ${ }^{3031}$ adopting similar measures although with far fewer resources. Supervision of drug taking from the beginning of treatment has been extensively recommended when factors such as poverty, homelessness, intravenous drug abuse, or anticipation of non-compliance are present, otherwise a very low cure rate will be achieved. ${ }^{7-9}$ In tuberculosis control programmes for high risk groups developed in Gran Canaria in 1988 and $1989^{32} 87 \%$ and $83 \%$, respectively, of the patients abandoned antituberculosis treatment. These findings, and the results of the present study in which low compliance at two months was the only variable significantly associated with abandonment of treatment, further confirm the importance of directly observed administration of drugs. It is therefore necessary to develop special compliance-related strategies for high risk populations (such as those described in this study) including supervision of drug taking in patients on methadone maintenance programmes. ${ }^{33}$

According to the recommendations of the American Thoracic Society, ${ }^{34}$ for a short term chemotherapy strategy to be considered acceptable both therapeutic failures and relapses should not exceed $5 \%$ and adverse effects of treatment should not cause a change in the therapeutic regimen in more than $5 \%$ of patients. The present results fulfil these specifications (no failures, relapse rate of $3.4 \%$ in 88 patients followed for over two years after completion of treatment, $1.9 \%$ adverse effects) and the high rate of negative cultures at the end of the second month (94.7\%) confirms the effectiveness of six months of fully intermittent (twice weekly) tuberculosis treatment. These figures are similar to those obtained in islanders treated with a standard course of medication. ${ }^{32}$

The main problems with the treatment of tuberculosis are supervision of the patients until they are cured and the cost of achieving this in developing countries. Both problems could be solved with the supervised treatment under study as it would be necessary to observe 52 drug administrations directly to control the entire treatment, fewer than the 60 that would be needed for daily supervision during the first two months of the recommended regimens by the International Union against Tuberculosis and Lung Disease and the World Health Organisation. ${ }^{4513143536}$ On the other hand, doses of rifampicin (the most expensive drug) in the intermittent regimen are equal to those used in daily regimens. This, together with the fact that treatment is provided on an outpatient basis, results in a substantial reduction in the cost of treatment.

In summary, this study shows the effectiveness of a fully intermittent antituberculosis regimen from the beginning of treatment, and the efficiency of an incentive programme in 
which administration of the medication was directly supervised by the nursing staff. This regimen may constitute a valuable strategy in tuberculosis control programmes in developing countries and for treating high risk patients in whom non-compliance is anticipated, especially in industrialised countries.

This study was supported by a grant from Sociedad Española de Patologia Respiratoria (SEPAR). We thank Elena Torres, Candelaria Robaina and Maria Escobar who were responsible for supervising drug taking and Dr Marta Pulido for editing the manuscript and editorial assistance.

1 Enarson DA. Principles of IUATLD collaborative tuberculosis programme. Bull Int Union Tuberc Lung Dis 1991; 66:195-200.

2 World Health Organization. WHO Expert Committee on tuberculosis. Ninth report. Geneva: World Health Organization, 1974.

3 Caminero JA. Medidas básicas para el control de la tuberculosis en una communidad. Med Clin (Barc) 1994;102: 67-73.

4 Chum HJ. The Tanzania National Tuberculosis/Leprosy Programme in the face of HIV infection. Bull Int Union Tuberc Lung Dis 1990/1991;66(Suppl):53-5.

5 Arguello L. Results of the tuberculosis control programme in Nicaragua in 1984-1989. Bull Int Union Tuberc Lung Dis 1990/1991;66(Suppl):51-2.

6 Medical Research Council Tuberculosis and Chest Diseases Unit. Treatment of pulmonary tuberculosis in patients notified in England and Wales in 1978-9: chemotherapy and hospital admission. Thorax 1985;40:113-20.

7 Brudney K, Dobkin J. Resurgent tuberculosis in New York City. Human immunodeficiency virus, homelessness, and the decline of tuberculosis control programs. Am Rev Respir Dis 1991;144:745-9.

8 Prevention and control of tuberculosis among homeless persons. Recommendations of the Advisory Council for the Elimination of Tuberculosis. $M M W R$ 1992;41 (RR 5): 13-23.

9 Ferrer X, Kirschbaum A, Toro J, Jadue J, Munoz M, Espinoza A. Compliance with tuberculosis treatment in adults in Santiago, Chile. Bol Sanit Panam 1991;111: 423-31.

10 Joint Tuberculosis Committee of the British Thoracic Society. Control and prevention of tuberculosis in the United Kingdom: code of practice 1994. Thorax 1994;49:1193 200 .

11 Jindani A, Aber VR, Edwards EA, Mitchison DA. The early bactericidal activity of drugs in patients with pulmonary tuberculosis. Am Rev Respir Dis 1980;121:939-49.

12 Mitchison DA. Basic mechanisms of chemotherapy. Chest 1979;76(Suppl):771-81.

13 Subcommittee of the Joint Tuberculosis Committee. Chemotherapy and management of tuberculosis in the United Kingdom; recommendations of the Joint Tuberculosis Committee of the British Thoracic Society. Thorax culosis Commit

14 American Thoracic Society. Treatment of tuberculosis and tuberculosis infection in adults and children. $A m \mathcal{F}$ Respir Crit Care Med 1994;149:1359-74.

15 International Union Against Tuberculosis and Lung Diseases. Committee of Treatment. Bull Int Union Tuberc Lung Dis 1988;63:64.

16 World Heath Organisation. Treatment of tuberculosis. Guidelines for national programmes. Geneva: World Health Organization, 1993.
17 Caminero JA, González A, Rodriguez de Castro F, Juliá G, Fernández JM, Cabrera P. Epidemiología de las resistencias bacilares en la isla de Gran Canaria. Arch Bronconeumol 1991;27:17-22.

18 Ministerio de Sanidad y Consumo. Grupo de trabajo sobre tuberculosis. Consenso nacional para el control de la tuberculosis en España. Med Clin (Barc) 1992;98:24-31.

19 Canetti G, Rist N, Grosset J. Mesure de la sensibilite du bacille tuberculeux aux drogues antibacilaires par le 263-72.

20 Second East African/British Medical Research Council study. Controlled clinical trial of four short-course ( 6 month) regimens of chemotherapy for treatment of pulmonary tuberculosis. Lancet 1974;ii:1100-6.

21 Second East African/British Medical Research Council study. Controlled clinical trial of four short-course $(6$ month) regimens of chemotherapy for treatment of pulmonary tuberculosis. Second report. Am Rev Respir Dis 1976;114:471-5.

22 Hong Kong Chest Service/British Medical Research Council. Controlled trial of six-month and eight-month regimens in the treatment of pulmonary tuberculosis. First report. Am Rev Respir Dis 1978;118:219-27.

23 Hong Kong Chest Service/British Medical Research Council. Controlled trial of four twice-weekly regimens and daily regimen all given for six months for pulmonary tuberculosis. Lancet $1981 ; \mathrm{i}: 171-4$

24 Hong Kong Chest Service/British Medical Research Council. Controlled trial of four three times weekly regimens and daily regimen all given for six months for pulmonary tuberculosis. Tubercle 1982;63:89-98.

25 Hong Kong Chest Service/British Medical Research Council. Five year follow-up of a controlled trial of five sixmonth regimens of chemotherapy for pulmonary tuberculosis. Rev Respir Dis 1987;136:1339-42.

26 Eule H, Beck H, Evers A. Daily and intermittent shortcourse chemotherapy using four drugs in recently detected bacillary pulmonary tuberculosis. Bull Int Union Tuberc Lung Dis 1982;52:63.

27 Prabhakar H. Fully intermittent six-month regimen for pulmonary tuberculosis in South India. Bull Int Union Tuberc Dis $1987 ; 62: 21-3$.

28 Paramasivan CN, Chandrasekaran V, Santha T, Sudarsanan NM, Prabhakar R. Bacteriological investigations for shortcourse chemotherapy under the tuberculosis programme in two districts of India. Tuberc Lung Dis 1993;74:23-7.

29 Datta M, Radhamani MP, Selvarag R, Paramasivan CN, Gopalan BN, Sudeendra CR, et al. Clinical assessment of smear-positive pulmonary tuberculosis patients after chemotherapy under the district tuberculosis programme. Tuberc Lung Dis 1993;74:180-6.

30 Giullani RW, Hamburg MA. New tuberculosis cases declined in 1993, Department of Health announces. New York: News of the Department of Health of New York, 1994.

31 Frieden TR, Fujiwara PI, Washko RM, Hamburg MA Tuberculosis in New York city. Turning the tide. $N$ Engl Tuberculosis in New York

32 Caminero JA. Elaboración de un programa de control de la tuberculosis en la isla de Gran Canaria. Universidad de Las Palmas (España): Doctoral thesis, 1993

33 Caylá JA, Galdós-Tangüis $\mathrm{H}$, García de Olalla $\mathrm{P}$, Rodrigo T, Brugal MT, Jansá JM. La tuberculosis en Barcelona. Informe 1993. Barcelona: Publicaciones del Institut Municipal de la Salut, 1994.

34 American Thoracic Society. Guidelines for short-course tuberculosis chemotherapy. Am Rev Respir Dis 1980;121: $611-4$.

35 Nyangulu DS. The point of view of a high prevalence country: Malawi. Bull Int Union Tuberc Lung Dis 1991;66: 173-4.

36 Salomao MA. The national tuberculosis control programme in Mozambique, 1985-1990. Bull Int Union Tuberc Lung Dis $1991 ; 66: 175-80$. 